\title{
CEA-negative glioblastoma and melanoma cells are sensitive to cytosine deaminase/5-fluorocytosine therapy directed by the carcinoembryonic antigen promoter
}

Anna Dąbrowska ${ }^{1,3}$, Jarosław Szary ${ }^{2}$, Małgorzata Kowalczuk ${ }^{2}$, Stanisław Szala ${ }^{2}$ and Maciej Ugorski ${ }^{1 凶}$

${ }^{1}$ Department of Immunochemistry, Institute of Immunology and Experimental Therapy, Polish Academy of Sciences, Wroctaw, Poland; ${ }^{2}$ Department of Tumour Biology, Institute of Oncology, Gliwice, Poland; ${ }^{3}$ Faculty of Food Science, Agriculture University, Wroctaw, Poland

Received: 16 February, 2004; revised: 21 April, 2004; accepted: 04 May, 2004

Key words: gene-directed enzyme prodrug therapy, E. coli cytosine deaminase, CEA promoter

\begin{abstract}
Recent studies have suggested that carcinoembryonic antigen (CEA)-promoter sequences are active only in CEA-positive cells, filing in the criteria for tumor specific targeting of suicide genes. However, the present study on gene therapy of colon cancer and cell-specificity of CEA promoter, provide evidence that CEA-positive and CEA-negative cells transfected with $E$. coli cytosine deaminase $(C D)$ gene under the control of CEA promotor sequence are sensitive to enzyme/pro-drug therapy with 5-fluorocytosine (5-FC). Individual clones derived from the CEA-negative cell lines: melanoma Hs294T and glioblastoma T98G after transfection with $C D$ differed profoundly in their sensitivity to 5 -FC. The $\mathrm{IC}_{50}$ values for several clones of the CEA-negative cells were almost the same as for CEA-positive colon cancer cells. Such 5-FC-sensitive clones derived from the population of CEA-negative cells, present even in small number, because of the very effective bystender effect of this enzyme/pro-drug system can cause severe problems during therapy by efficiently killing surrounding normal cells. Safety is the major issue in gene therapy. Our data suggest that the safety of gene-directed enzyme pro-drug therapy (GDEPT) with CEA promoter driven expression of therapeutic genes is not so obvious as it has originally been claimed.
\end{abstract}

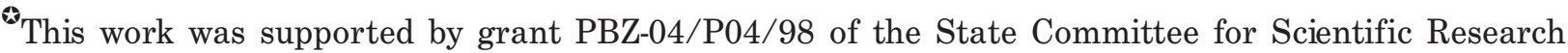
(KBN, Poland).

${ }^{凶}$ Corresponding author: Maciej Ugorski, Department of Immunochemistry, Institute of Immunology and Experimental Therapy, Polish Academy of Sciences, Weigla Street 12, 53-114 Wrocław, Poland; tel.: (48 71) 337 1172; fax: (48 71) 337 1382; e-mail: ugorski@immuno.iitd.pan.wroc.pl

Abbreviations: CEA, carcinoembryonic antigen; CD, cytosine deaminase; 5-FC, 5-fluorocytosine; GDEPT, gene-directed enzyme pro-drug therapy; HPRT, human hypoxanthine guanine phosphoribosyltransferase; HSV-TK, herpes simplex virus thymidine kinase; SRB, sulforhodamine B.
} 
Colon carcinoma is one of the leading causes of mortality due to malignancy in Europe and North America (Finkelstein et al., 1993; Chung-Faye et al., 2000). The presently used methods to treat colon cancer, including surgical operations, chemotherapy and immunotherapy, are not satisfactory, with a large number of patients dying because of recurrent disease. For these reasons there is an urgent need for development of new strategies, including gene therapy. One of the latter is gene-directed enzyme pro-drug therapy (GDEPT) which seems to be a promising approach to treat colon carcinoma (Moolten et al., 1986; Freeman et al., 1996). In this system of somatic gene therapy, an enzyme of nonmammalian origin introduced into the cancer cell converts a nontoxic drug to a cytotoxic product. Escherichia coli cytosine deaminase (CD) converting 5 -fluorocytosine (5-FC) to 5-fluorouracil (Mullen et al., 1994; Huber et al., 1994) or herpes simplex virus thymidine kinase (HSV-TK) transforming an acyclic nucleoside, ganciclovir, to its monophosphate (Moolten et al., 1986; 1990) are examples of suicide genes. Successful GDEPT is dependent on the effective and specific expression of such genes only in cancer cells. This can be achieved using tumor cell-specific promoters of genes coding for tumor-associated antigens. A good example of such $5^{\prime}$ transcriptional regulatory elements is carcinoembryonic antigen (CEA) gene promoter used to express the transgene only in tumor cells producing CEA (Richards et al., 1995; Cao et al., 1998; Fichera et al., 1998; Kurane et al., 1998).

Carcinoembryonic antigen belongs to the immunoglobulin superfamily that includes proteins with important biological functions, e.g. recognition units of the immunological system and adhesion molecules (Holness \& Simmons, 1994). CEA is a cell surface glycoprotein of 180-200 kDa molecular mass, present in low amounts in several types of normal epithelial cells (Cournoyer et al., 1988; Thompson et al., 1991). Its highly in- creased expression is most often associated with colon, stomach, pancreas, lung and breast cancers (Shively \& Beatty, 1985; Thompson et al., 1991). Monitoring of CEA serum level has important prognostic value for postoperative surveillance as well as for chemotherapy and immunotherapy efficacy determination (Shiveley et al., 1985; Seregni et al., 1992).

As it was shown previously, the expression of suicide genes, $E$. coli $C D$ and $H S V$-tk, under the transcriptional control of CEA promoter sequences, is limited to CEA-positive colon (Richards et al., 1995; Cao et al., 1999a; 1999b; Ueda et al., 2000), gastric (Tanaka et al., 1996; 1997), lung (Osaki et al., 1994; Kijma et al., 1999), pancreatic (DiMaio et al., 1994) and cholangiocarcinoma cells (Tanaka et al., 2000). In contrast, the CEA-negative lung carcinoma A549 cells (Osaki et al., 1994), gastric cancer MKN1 cells as well as renal carcinoma RC9406 and cervix carcinoma HeLa cells (Cao et al., 1999a) do not express reporter or suicide genes when their expression is directed by CEA promoter. These data strongly suggest that CEA promoter sequences are active only in CEA-positive cells, fulfilling the criteria for tumor specific targeting of suicide genes. However, in the present study we obtained unexpected results showing that CEA-negative glioblastoma and melanoma cells are highly sensitive to 5 -FC when the $E$. coli $C D$ gene's expression is directed by CEA promoter.

\section{MATERIALS AND METHODS}

Cells and cell culture. Human colon carcinoma cell line CX-1 was obtained from Deutsche Krebsforschungszentrum (Heidelberg, Germany). Other human cell lines, colon carcinoma HT-29, lung carcinoma A549, melanoma Hs294T and glioblastoma T98G, were obtained from the Cell Line Collection of the Institute of Immunology and Experimental Therapy (Wroclaw, Poland). CX-1, HT-29 and 
A549 cells were cultured in $\alpha$-minimal essential medium ( $\alpha$-MEM), T98G, in Eagle minimal essential medium, Hs294T, in Dulbecco's modified Eagle medium (D-MEM). The media were supplemented with $10 \%$ fetal calf serum (Gibco BRL), $2 \mathrm{mM}$ glutamine and antibiotics (complete media).

Transient transfection and reporter activity assays. Carcinoma cells $\left(5 \times 10^{4}\right)$ were seeded on 24-well culture plates. After overnight culture they were co-transfected with pGL3-Basic Vector containing the CEA promoter region (pGL3/CEA) and pRL-TK plasmid containing the herpes simplex virus thymidine kinase promoter region, using Fugene 6 Reagent (Roche). Control cells were co-transfected with control pGL3 Promoter Vector containing an SV40 promoter and pRL-TK plasmid. The plasmids were obtained from Promega. The pGL3/CEA plasmid (1.8 $\mu \mathrm{g})$ or pGL Promoter Vector $(1.8 \mu \mathrm{g})$ and pRL-TK plasmid $(0.2 \mu \mathrm{g})$ in $50 \mu \mathrm{l}$ of Opti-minimal essential medium I (OPTI-MEM, Gibco BRL) were mixed with $6 \mu$ l Fugene 6 Reagent diluted with $100 \mu \mathrm{l}$ OPTI-MEM and incubated for $30 \mathrm{~min}$ at room temperature. After incubation the resulted solution, diluted with $1 \mathrm{ml}$ of OPTI-MEM, was added to the cells and after another 5 -h incubation replaced with fresh complete $\alpha$-MEM for CX-1, HT-29 and A549 cells, complete D-MEM for Hs294T cells and complete Eagle minimal essential medium for T98G cells. Cells were harvested after $48 \mathrm{~h}$ and firefly (Photinus pyralis) and renilla (Renilla reniformis) luciferase activities were measured using Dual-Luciferase Reporter Assay System (Promega). The experiments were performed in triplicates.

Flow cytometry analysis. Cells $\left(2 \times 10^{4}\right)$, detached with $0.2 \%$ EDTA, were resuspended in TBS-BSA (50 mM Tris/ $\mathrm{HCl}, 180 \mathrm{mM} \mathrm{NaCl}$, $5 \mathrm{mM} \mathrm{CaCl}_{2}, 18 \mathrm{mM} \mathrm{MgSO}_{4}$ containing $1 \%$ BSA and $0.1 \% \mathrm{NaN}_{3}$ ) and incubated with monoclonal antibody 26/3/13, specific for CEA (Grunert et al., 1985) for $1 \mathrm{~h}$ on ice. After washing, the cells were incubated with fluorescein-isothiocyanate (FITC)-conjugated rabbit $\mathrm{F}(\mathrm{ab})_{2}$ fragment against mouse immunoglobulins (DAKO) for another hour on ice.

The cells were analyzed for positive staining by flow cytometry, using FACScan (BectonDickinson). Five thousand cells were acquired for each datafile. Data were processed and mean fluorescence intensity calculated using WinMDI 2.0.4 (1995).

CEA measurement. The level of secreted CEA in culture supernatants of growing tumor cells was quantified using a commercial immunometric assay (Immunolite CEA,' Euro/Diagnostic Products Corporation).

RNA analysis. Total RNA was isolated from about $10^{7}$ cells with the use of NucleoBond RNA/DNA 400 kit (MarcheryNagel). To remove contaminants of genomic DNA, purified material was digested with Deoxyribonuclease I kit (Sigma-Aldrich). Reverse transcription reactions were performed using Omniscript Reverse Transcriptase, Buffer RT, 0.1 M dithiothreitol (DTT) and Oligo(dT) 12-18, according to the conditions recommended by the manufacturer (Qiagen $\mathrm{GmbH})$. The reaction mixtures for PCR contained: PCR buffer, 2.5 U Taq DNA polymerase (Qiagen $\mathrm{GmbH}$ ) and $2 \mu \mathrm{M}$ of each deoxynucleotide (Sigma-Aldrich). CEA $471 \mathrm{bp}$ cDNA fragment was amplified with primers: 5'-CCG AAG CTT CAG ATG GTG CAT CCC-3' (CEA1) and 5'-CGC GAA TTC CTT GTC CTC CAC GGG T-3' (CEA2) (Bionovo). Human hypoxanthine guanine phosphoribosyl transferase (HPRT) 556 bp cDNA fragment was amplified with primers: 5 '-CCG TTC TCC CCT CCA TCG-3' (Hprt-1) and 5'-CAG GTT ACA TGG TGG TGC-3' (Hprt-2) (Bionovo).

Construction of pBCMGSNeo/CD/CEA vector and transfections. Plasmid $\mathrm{pCEA}-$ TK-S containing a $424 \mathrm{bp}$ fragment of human CEA promoter was kindly provide by Dr. Yoshiro Tanio (Osaka University Medical School, Japan). The CEA promoter from pCEATK-S plasmid was obtained by digestion with $B g l I I$ followed by generating of blunt 
ends with mung bean nuclease and subsequent digestion with SalI. The resulting fragment was ligated into pBluescript $\mathrm{SK}+$ plasmid (Stratagene) digested with SmaI and SalI. To construct pGL3/CEA plasmid the SacI-XhoI fragment from pBluescript SK+/CEA was subcloned into pGL3Basic vector (Promega). Construction of the expression vector encoding $E$. coli cytosine deaminase under the control of CMV promoter (pBCMGSNeo/CD/CMV) was described earlier (Szala et al., 1996). To construct a plasmid encoding $E$. coli cytosine deaminase under the control of CEA promoter, the CMV promoter was removed from pBCMGSNeo/CD/CMV by digestion with $X b a \mathrm{I}$ and SalI. The CEA promoter from pBluescript/CEA digested with the same restriction enzymes was then ligated in place of CMV promoter thus generating pBCMG$\mathrm{SNeo} / \mathrm{CD} / \mathrm{CEA}$ vector.

Human cell lines were transfected using Fugene 6 Reagent. DNA $(4.5 \mu \mathrm{g}$ in $50 \mu \mathrm{l}$ of OPTI-MEM) was mixed with $12 \mu$ l Fugene 6 Reagent diluted with $100 \mu \mathrm{l}$ OPTI-MEM. After $30 \mathrm{~min}$ at room temperature the solution, diluted with $5 \mathrm{ml}$ OPTI-MEM, was added to $10^{6}$ cells grown in 100 -mm culture dishes. After 5-h incubation, the transfection mixture was replaced with fresh complete medium and then after overnight culture replaced again with complete medium containing 1 $\mathrm{mg} / \mathrm{ml}$ G418 (Gibco BRL) for CX-1, HT-29, A549 and T98G cells, or $0.8 \mathrm{mg} / \mathrm{ml} \mathrm{G418} \mathrm{for}$ Hs294T cells. After 4-5 weeks individual colonies were isolated and propagated. The cell clones obtained were maintained in the presence of G418 $(0.25 \mathrm{mg} / \mathrm{ml})$.

Drug sensitivity assay (SRB assay). The sensitivity of tumor cells, native and $C D$-transfected, to 5 -FC was assessed using proliferation assay described by Skehan et al. (1990). Briefly, cells $\left(5 \times 10^{3} /\right.$ well $)$ were seeded in 96-well plates (Saerstedt) in suitable complete medium. Next day they were incubated with increasing amounts of 5-FC for $72 \mathrm{~h}$. Then the cells were fixed by cold $50 \%$ trichloric acid (POCH, Gliwice, Poland). After washing, they were incubated with $0.4 \%$ sulforhodamine B (SRB, Sigma-Aldrich) in $1 \%$ acetic acid for $30 \mathrm{~min}$, rinsed 4 times with $1 \%$ acetic acid and the protein-bound dye was extracted with $10 \mathrm{mM}$ Tris. The absorbance at $540 \mathrm{~nm}$ was measured in a Multiscan RC photometer (Labsystem). The experiment was performed in triplicate.

\section{RESULTS}

\section{CEA promoter activity in human cancer} cell lines

The promoter activity was measured in the analyzed cancer cells after their transfection with pGL3/CEA plasmid, using luciferase assay. The highest luciferase activity was found in human colon carcinoma HT-29 cells (Fig. 1). Also a considerable level of luciferase

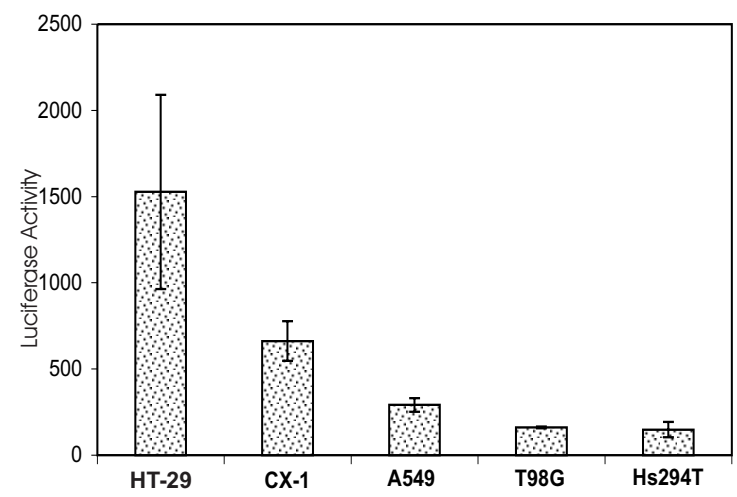

Figure 1. Luciferase activity in pGL3/CEA-transfected human carcinoma cell lines.

Bars represent average luciferase activities compared to the control vector pGL3 containing SV40 promoter. Standard deviations from triplicate assays are indicated at the top of each bar.

expression was detected in the second colon carcinoma cell line CX-1, derived from HT-29 cells (Wagner et al., 1992); however, the CEA promoter activity was about 3 times lower than in the parental line. Some activity of luciferase was found in lung carcinoma A549 as 

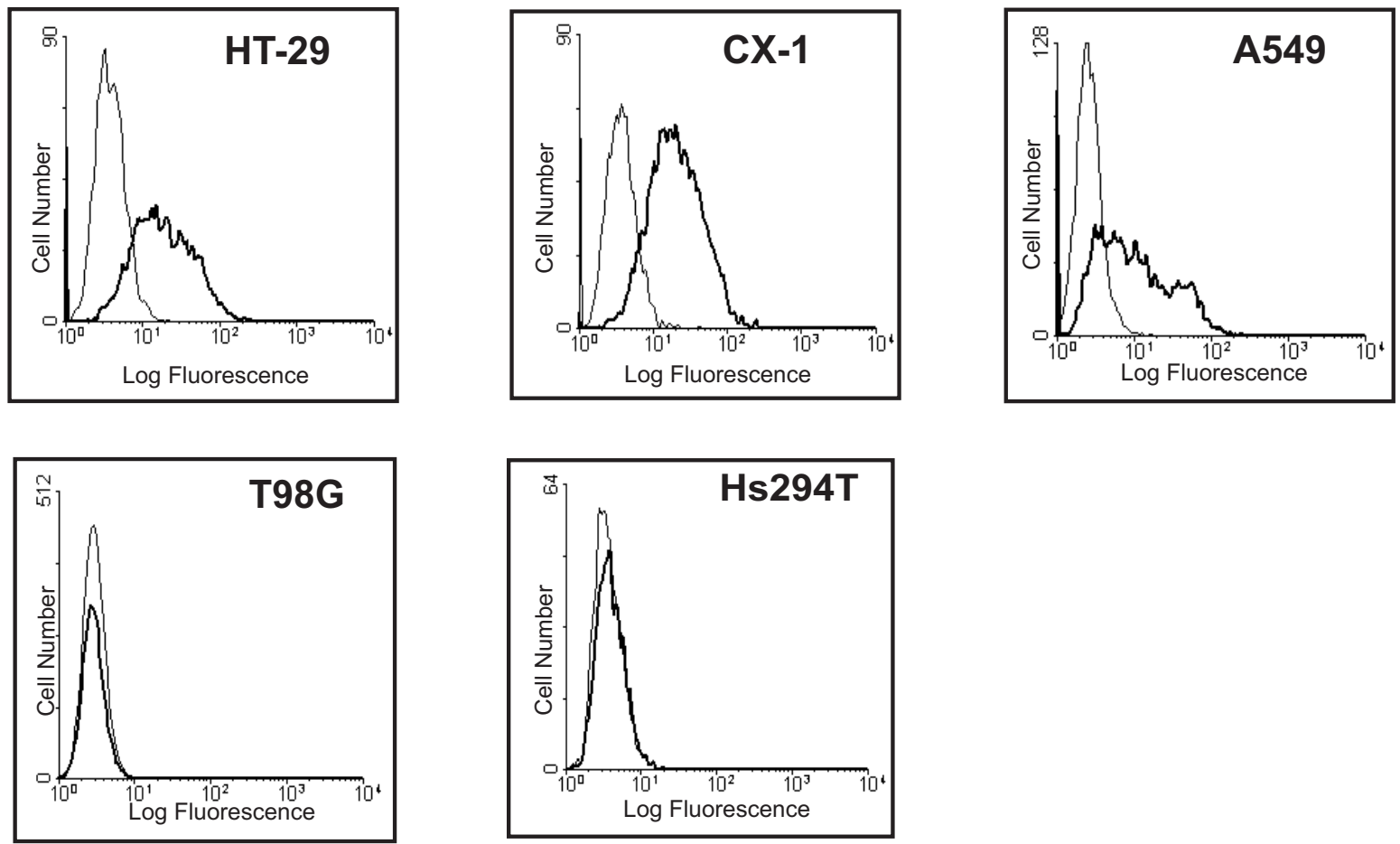

Figure 2. Flow cytometric analysis of CEA in human carcinoma cell lines.

Thick lines show the binding of anti-CEA mAb 26/3/13; thin lines, non-specific binding of secondary goat antibody anti-mouse immunoglobulins.

well as in melanoma $\mathrm{Hs} 294 \mathrm{~T}$ and glioblastoma T98G cells.

\section{Expression of CEA by tumor cell lines}

The expression of CEA on the surface of human cancer cells was studied by flow cytometry. As it was shown previously $\mathrm{mAb}$ 26/3/13 bound strongly to human colon carcinoma CX-1 cells (Fig. 2) (Krop-Wątorek et al., 1999). High binding of this CEA-specific anti-

Table 1. CEA production by human cancer cell lines

\begin{tabular}{ll}
\hline Cell line & $\begin{array}{l}\text { CEA production } \\
\text { ngCEA/10 cells per ml }\end{array}$ \\
\hline HT29 & 21.3 \\
CX-1 & 23 \\
A549 & 3.2 \\
T98G & 0.65 \\
Hs294T & 0.53 \\
\hline
\end{tabular}

body was also observed for HT-29 cells and a lower one to lung carcinoma A549 cells. mAb 26/3/13 did not react with melanoma Hs294T and glioblastoma T98G cells. The data obtained for membrane-bound CEA correlated well with the results obtained for secreted CEA (Table 1).

\section{RNA analysis by reverse-transcriptase PCR}

The presence of the CEA gene transcript in the analyzed cell lines was detected by reverse-transcriptase PCR. Before reverse transcription, isolated total RNA was subjected to digestion with DNase I. To compare the level of expression of CEA mRNA, semi-quantitative PCR with the PCR product for HPRT as an internal standard was used. As expected, CEA transcript was detected in colon cancer cell lines HT-29 and CX-1 (Fig. 3). Interestingly, no CEA mRNA was detectable in lung carcinoma A549 cells, however, a PCR product obtained with CEA-specific primers was 


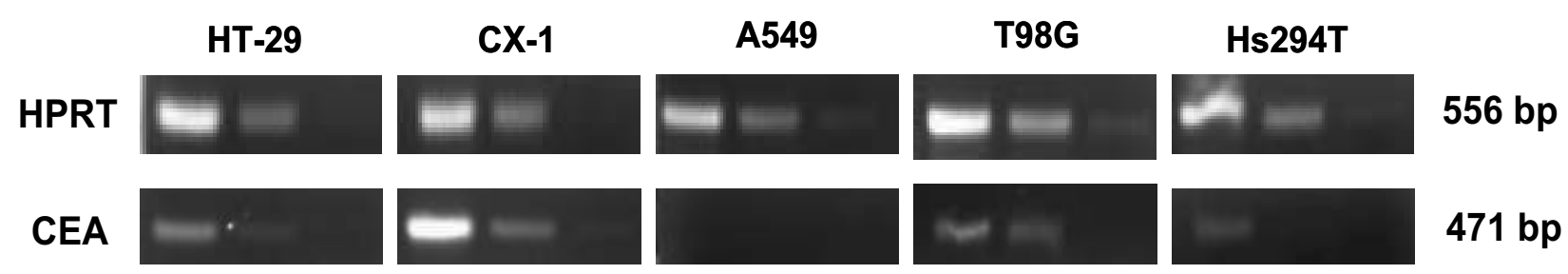

Figure 3. Reverse-transcriptase PCR analysis of human carcinoma cell lines.

Amplified cDNA samples were electrophoresed in $1 \%$ agarose and stained with ethidium bromide. Individual bands represent different dilutions of cDNA templates for $\operatorname{HPRT}(1,10$ and $100 \times)$ and for CEA (1, 10 and $100 \times)$. On the right, the sizes of the PCR products are indicated.

found in glioblastoma T98G and melanoma Hs294T cells.

\section{In vitro 5-FC sensitivity of human cancer} cell lines transfected with $E$. coli CD

The cell-specificity of CD expression under the control of CEA promoter was analyzed in a panel of CEA-producing and non-producing human carcinoma cell lines. The cancer cells were transfected with pBCMGSNeo/CD/CEA or pBCMGSNeo and selected for resistance to G418. Individual neomycin-resistant clones were harvested and expanded, and their sensitivity to 5-FC was analyzed by SRB assay. We found that individual clones derived from either of the analyzed cell lines after transfection with $E$. coli $C D$ differed profoundly in their resistance to the pro-drug. Independently of the level of CEA expression, there were clones which were totally resistant to 5-FC with the same $\mathrm{IC}_{50}$ as cells transfected with the vector alone, as well as clones highly sensitive to this pro-drug. The results of growth inhibition studies, after $72 \mathrm{~h}$ of incubation in the presence of increasing amounts of 5-FC, for the selected cell clones are shown in Fig. 4.

\section{DISCUSSION}

Successful gene therapy based on drug sensitization is dependent on strong and cell-spe- cific expression of suicide genes. For colorectal carcinoma two such systems, combination of $E$. coli cytosine deaminase (CD) and 5-fluorocytosine (5-FC) or herpes simplex virus thymidine kinase (HSV-TK) and ganciclovir have been widely studied. It has been shown by several authors that specific expression of $C D$ or $H S V$-tk genes in colon as well as other cancer cells can be achieved with a vector delivery system containing CEA promoter sequences. A promoter region of 440 bp was originally cloned by Schreve et al. (1990) who showed that this $5^{\prime}$ regulatory sequence has a higher activity in CEA-positive cells than in the CEA-negative HeLa cells. Consequently this promoter was used in gene therapy to direct the expression of suicide genes in CEA-expressing cells. CEA promoter driven expression of HSV-TK and/or CD was described in pancreatic cancer (DiMaio et al., 1994), gastric cancer (Tanaka et al., 1996; Lan et al., 1996; Ueda et al., 2003), lung cancer (Osaki et al., 1994) and colon (Fischera et al., 1998). It was shown further by Cao et al. (1999b) that essentially the same CEA 5' transcriptional regulatory sequence located from -309 to $+110 \mathrm{bp}$ from the transcription start site gives more stringent cell-specific expression of CEA in comparison with the CEA promoter region encompassing to -135 to +69 bp. A detailed analysis of $5^{\prime}$ transcriptional regulatory sequences of the CEA gene was performed by Richards et al. (1995). They have shown that multimerization of the 

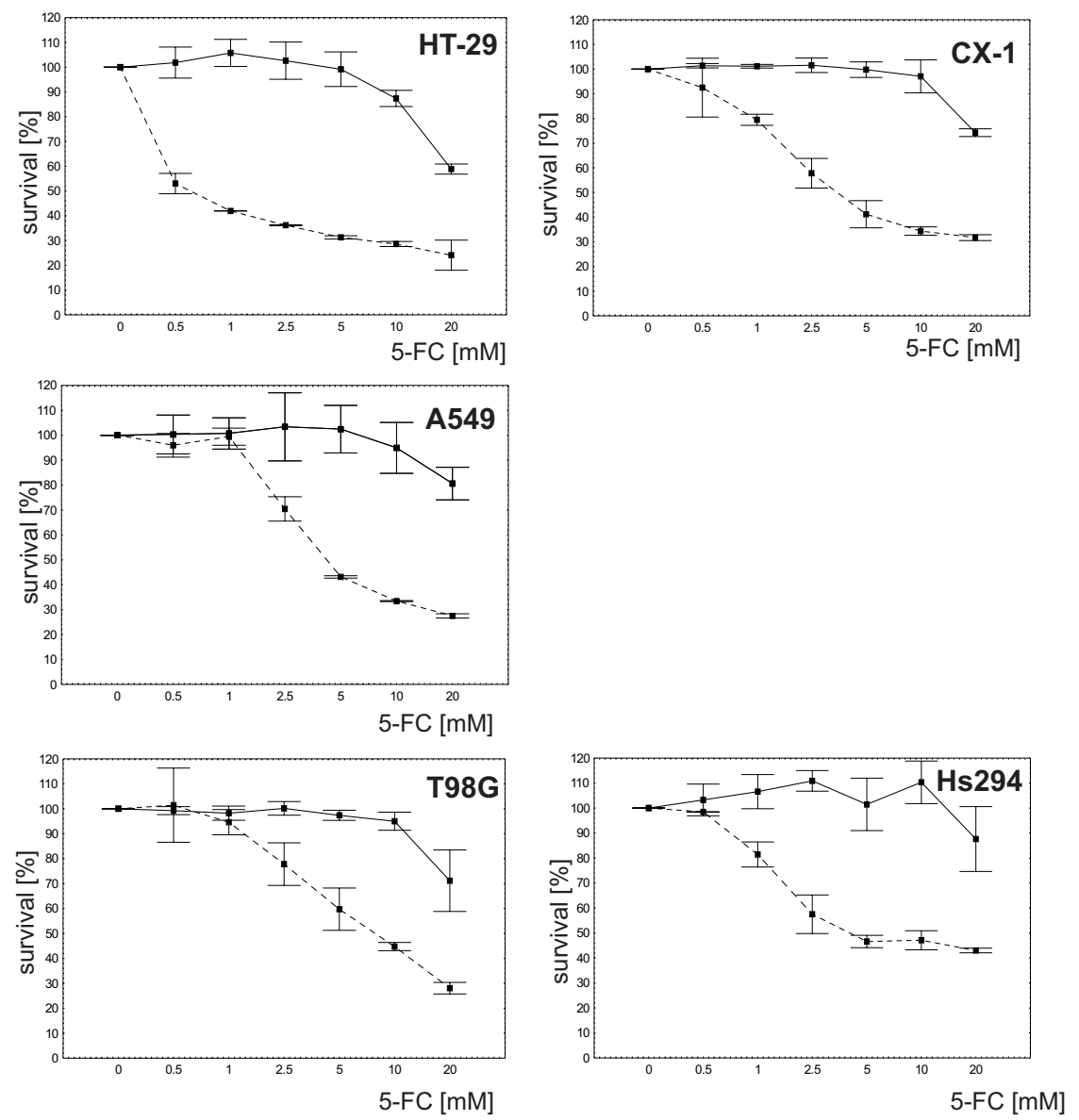

Figure 4. $\mathrm{IC}_{50}$ for 5-FC of human cancer cell lines transfected with $E$. coli $C D$ gene under the control of CEA promoter.

HT-29/Neo, CX-1/Neo, A549/Neo, T98G/Neo, Hs294T/Neo - cells transfected with vector alone (solid line); HT-29/CD/CEA, CX-1/CD/CEA, A549/CD/CEA, T98G/CD/CEA, Hs294T/CD/CEA - cells transfected with CD gene under the control of CEA promoter (dashed line). Cancer cells were grown in the presence of increasing concentrations of 5-FC for $72 \mathrm{~h}$. Cell growth was assessed by SRB assay.

promoter sequence -89 to -40 and then ligation of such a sequence with its specific enhancer sequences resulted in an increase in the expression level as well as specificity for CEA-positive cells.

However, the specificity of reporter or suicide gene expression directed by CEA promoter was studied in only a few types of CEA-negative cells, namely gastric cancer MKN1 (Tanaka et al., 1996), lung cancer A549 and CADO-LC9 (Osaki et al., 1994), cholangiocarcinoma SSP-25 (Tanaka et al., 1996), renal carcinoma RC 9406, hepatocellular carcinoma Hep3B (Cao et al., 1999a), HeLa (Tanaka et al., 1997) and 293 embryonal (Kijma et al., 1999). In addition, several authors claimed that the use of CEA promoter ensures safety of human gene therapy based on the results obtained from nude mice model. They have shown that the expression of cytosine deaminase is limited only to human tumor xenografts when nude mice implanted with colorectal carcinoma or gastric cancer were inoculated with viral vectors carrying suicide $(C D)$ or reporter ( $\beta$-galactosidase) genes directed by CEA promoter (Ueda et al., 2003; Cao et al., 1999a; Lan et al., 1998). These results, however, have to be treated with caution because there is no obvious reason why the CEA promoter of human origin should be expressed in murine tissues, in contrast to human tissues. 
In our studies on gene therapy of colon carcinoma, the CEA promoter region encompassing -316 to $+107 \mathrm{bp}$ (Osaki et al., 1994) was cloned in pBCMGSNeo/CD/CEA plasmid to direct the expression of $E$. coli CD. In contrast to the authors cited above, we found that not exclusively CEA-positive cells were sensitive to the enzyme/pro-drug therapy with 5-FC. Our experiments revealed that individual clones derived from the CEA-negative cell lines: melanoma $\mathrm{Hs} 294 \mathrm{~T}$ and glioblastoma T98G after transfection with $E$. coli $C D$ can differ profoundly in their sensitivity to 5 -FC. The $\mathrm{IC}_{50}$ estimated for several clones of CEA-negative cells were almost the same as for the CEA-positive cells. Interestingly, similar results were obtained by Lan $e t$ al. (1996). They showed that among the CEA-negative MKN1 gastric cancer cells transduced with adenovirus vector carrying lacZ gene under the control of CEA promoter a few cells stained positively for $\beta$-galactosidase. The presence of just a small fraction of cell clones highly sensitive to 5 -FC in a population of cells generally non-sensitive to the drug, should not affect to a great extent the safety of GDEPT therapy with CEA promoter driven expression of CD. However, because of the profound bystander effect of this enzyme/pro-drug system, such rare 5-FC-sensitive cells can cause severe problems by effectively killing surrounding normal cells.

The question remains what are the possible reasons of such unexpected results. T98G glioblastoma and Hs294T melanoma cells do not express membrane bound CEA, however, trace amounts of a secreted form of this glycoprotein were found in culture supernatants. In accordance with these results some promoter activity was also found in these two cell lines. Heterogeneity of cancer cells is a well known phenomenon, so it is possible that a small fraction of cells actually express the CEA gene. This is supported by the presence of CEA transcript as it was shown by RT-PCR. Thus we can expect that in those few cancer cells external CEA promoter intro- duced into the cells can be activated by the trans-acting elements (transcription factors) present in these cells.

Safety is the major issue in gene therapy, including the use of suicide genes. Our data suggest that the safety of GDEPT therapy with CEA promoter driven expression of therapeutic genes is not so obvious as has been claimed, and much more has to be done before such an approach can reach the stage of clinical trials.

\section{R E F E R E N C E S}

Cao G, Kuriyama S, Gao J, Mitoro A, Cui L, Nakatani T, Zhang X, Kikukawa M, Pan X, Fukui H, Qi Z. (1998) Comparison of carcinoembryonic antigen promoter regions isolated from human colorectal carcinoma and normal adjacent mucosa to induce strong tumor-selective gene expression. Int $J$ Cancer; 78: 242-7.

Cao G, Kuriyama S, Gao J, Kikukawa M, Cui L, Nakatani T, Zhang X, Tsujinoue H, Pan X, Fukui H, Qi Z. (1999a) Effective and safe gene therapy for colorectal carcinoma using the cytosine deaminase gene directed by the carcinoembryonic antigen promoter. Gene Ther:; 6: 83-90.

Cao G, Kuriyama S, Cui L, Nagao S, Pan X, Toyokawa Y, Zhang X, Nishiwaki I, Qi Z. (1999b) Analysis of the human carcinoembryonic antigen promoter core region in colorectal carcinoma-selective cytosine deaminase gene therapy. Cancer Gene Therapy.; 6: 572-80.

Chung-Faye GA, Kerr DJ, Young LS, Searle PF. (2000) Gene therapy strategies for colon cancer. Mol Med Today.; 6: 82-7.

Cournoyer D, Beauchemin N, Boucher D, Benchimol S, Fuks A, Stanners CP. (1988) Transcription of genes of the carcinoembryonic antigen family in malignant and nonmalignant human tissues. Cancer Res.; 48: 3153-7.

DiMaio JM, Clary BM, Via DF, Coveney E, Pappas TN, Lyerly HK. (1994) Directed en- 
zyme pro-drug gene therapy for pancreatic cancer in vivo. Surgery.; 116: 205-13.

Fichera A, Michelassi F, Arenas RB. (1998) Selective expression of carcinoembryonic antigen promoter in cancer strategy for gene therapy in colorectal cancer. Dis Colon Rectum.; 41: 747-54.

Finkelstein SD, Sayegh R, Christensen S, Swalsky PA. (1993) Genotypic classification of colorectal adenocarcinoma. Biologic behavior correlates with K-ras-2 mutation type Cancer.; 71: 3827-38.

Freeman SM, Whartenby KA, Freeman JL, Abboud CN, Marrogi AJ. (1996) In situ use of suicide genes for cancer therapy. Semin Oncol.; 23: 31-45.

Grunert F, AbuHarfeil N, Schwarz K, von Kleist S. (1985) Two CEA and three NCA species, although distinguishable by monoclonal antibodies, have nearly identical peptide patterns. Int $J$ Cancer.; 36: 357-62.

Holness CL, Simmons DL. (1994) Structural motifs for recognition and adhesion in members of the immunoglobulin superfamily. $J$ Cell Sci.; 107: 2065-70.

Huber BE, Austin EA, Richards CA, Davis ST, Good SS. (1994) Metabolism of 5-fluorocytosine to 5-fluorouracil in human colorectal tumor cells transduced with the cytosine deaminase gene: significant antitumor effects when only a small percentage of tumor cells express cytosine deaminase. Proc Natl Acad Sci USA.; 91: 8302-6.

Kijma T, Osaki T, Nishino K, Kumagai T, Funakoshi T, Goto H, Tachibana I, Tanio Y, Kishimoto T. (1999) Application of the Cre recombinase/loxP system further enhances antitumor effects in cell type-specific gene therapy against carcinoembryonic antigen-producing cancer. Cancer Res.; 59: 4906- 11 .

Krop-Wątorek A, Laskowska A, Salwa J, Kłopcki AG, Grunert F, Ugorski M. (1999) CEA-related proteins on human urothelial cell lines of different transformation grades. Cancer Lett.; 139: 15-22.
Kurane S, Krauss JC, Watari E, Kannagi R, Chang AE, Kudoh S. (1998) Targeted gene transfer for adenocarcinoma using a combination of tumor-specific antibody and tissue specific promoter. Jpn J Cancer Res.; 89: 1212-9.

Lan K-H, Kanai F, Shiratori Y, Okabe S, Yoshida Y, Wakimoto H, Hamada H, Tanaka T, Ohashi M, Omata M. (1996) Tumor-specific gene expression in carcinoembryonic antigen-producing gastric cancer cells using adenovirus vectors. Gastroenterology.; 111: 1241-51.

Lan K-L, Kanai F, Shiratori Y, Ohashi M, Tanaka T, Okudaira T, Yoshida Y, Hamada H, Omata M. (1998) In vivo gene expression and therapy mediated by adenoviral vectors for human carcinoembryonic antigen-producing gastric carcinoma. Cancer Res.; 57: 4279-84.

Moolten FL, Wells JM. (1990) Curability of tumors bearing herpes thymidine kinase genes transferred by retrovirus vectors. J Natl Cancer Inst.; 82: 297-300.

Moolten FL. (1986) Tumor chemosensitivity conferred by inserted herpes thymidine kinase genes: paradigm for a prospective cancer control strategy. Cancer Res.; 46: 5276-81.

Mullen CA, Coale MM, Lowe R, Blease RM. (1994) Tumors expressing the cytosine deaminase suicide gene can be eliminated in vivo with 5-fluorocytosine and induce protective immunity to wild-type tumor. Cancer Res.; 54: 1503-6.

Osaki T, Tanio Y, Tachibana I, Hosoe S, Kumagai T, Kawase I, Oikawa S, Kishimoto T. (1994) Gene therapy for carcinoembryonic antigen-producing human lung cancer cells by cell-specific expression of herpes simplex virus thymidine kinase gene. Cancer Res.; 54: 5258-61.

Richards CA, Austin EA, Huber BE. (1995) Transcriptional regulatory sequences of carcinoembryonic antigen: identification and use with cytosine deaminase for tumor-specific gene therapy. Hum Gene Ther.; 6: 881-93. 
Schreve H, Thompson J, Bona M, Hefta LJF, Maruya A, Hassayer M, Shively JE, von Kleist S, Zimmermann W. (1990) Cloning of the complete gene for carcinoembryonic antigen: analysis of its promoter indicates a region conveying cell type-specific expression. Mol Cell Biol.; 10: 2738-48.

Seregni E, Bombardieri E, Bogni A, Crippa F, Dejager E, Buraggi GL. (1992) The role of serum carcinoembryonic antigen (CEA) in the management of patients with colorectal carcinoma: the experience of the Instituto Tumori of Milan. Int $J$ Biol Markers.; 7: 167-70.

Shively JE, Beatty JD. (1985) CEA-related antigens: molecular biology and clinical significance. CRC Crit Rev Hematol.; 2: 355-99.

Skehan P, Storeng R, Scudiero D, Monks A, McMahon J, Vistica D, Warren JT, Bokesch H, Kenney S, Boyd MR. (199) 0New colorimetric cytotoxicity assay for anticancer-drug screening. $J$ Natl Cancer Inst.; 82: 1107-12.

Szala S, Missol E, Sochanik A, Stróżyk M. (1996) The use of cationic liposomes DC-CHOL/DOPE and DDAB/DOPE for direct transfer of Eschericha coli cytosine deaminase gene into growing melanoma tumors. Gene Therapy.; 3: 1026-31.

Tanaka T, Kanai F, Okabe S, Yoshida Y, Wakimoto H, Hamada H, Shiratori Y, Lan K-H, Ishitobi M, Omata M. (1996) Adenovirus-mediated prodrug gene therapy for carcinoembryonic antigen-producing human gastric carcinoma cells in vitro. Cancer Res.; 56: 1341-5.
Tanaka T, Kanai F, Lan K-H, Ohashi M, Shiratori Y, Yoshida Y, Hamada H, Omata M. (1997) Adenovirus-mediated gene therapy of gastric carcinoma using cancer-specific gene expression in vivo. Biochem Biophys Res Commun.; 231: 775-9.

Tanaka S, Iwai M, Morikawa T, Muramatsu A, Mori T, Okanoue Okanoue T, Kashima K, Maruyama-Tabata H, Hirai H, Satoh E, Imanishi J, Mazda O. (2000) Targeted killing of carcinoembryonic antigen (CEA)-producing cholangiocarcinoma cells by polyamidoamine dendrimer-mediated transfer of an Epstein-Barr virus (EBV)-based plasmid vector carrying the CEA promoter. Cancer Gene Ther.; 7: 1241-9.

Thompson JA, Grunert F, Zimmermann W. (1991) Carcinoembryonic antigen gene family: Molecular biology and clinical perspectives. J Clin Lab Anal.; 5: 344-66.

Ueda K, Iwahashi M, Nakamori M, Nakamura M, Yamaue H, Tanimura H. (2000) Enhanced selective gene expression by adenovirus vector using Cre/loxP regulation system for human carcinoembryonic antigen-producing carcinoma. Lab Invest.; 59: 255-65.

Ueda K, Iwahashi M, Nakamori M, Nkamura M, Matsuura I, Ojima T, Yamaue H. (2003) Improvement of carcinoembryonic antigen-specific prodrug gene therapy for experimental colon cancer. Surgery.; 133: 309-17.

Wagner HE, Toth CA, Steele GD Jr, Thomas P. (1992) Metastatic potential of human colon cancer cell lines: relationship to cellular differentiation and carcinoembryonic antigen production. Clin Exp Metastasis.; 10: 25-31. 